\title{
FAKTOR YANG MEMENGARUHI KEJADIAN EPILEPSI PASCASTROKE DI RSUP DR HASAN SADIKIN
}

\author{
FACTORS THAT INFLUENCE POSTSTROKE EPILEPSY IN \\ DR HASAN SADIKIN HOSPITAL \\ Indra Gunawan Affandi, * Suryani Gunadharma, * Anam Ong*
}

\begin{abstract}
Introduction: Stroke is the most commonly identified cause of epilepsy in adult. Stroke patients with cortical involvement, hemorrhagic stroke, severe neurological deficits and old age are factors which influence the incidence of poststroke epilepsy.

Aim: This research was to analyse factors which influence the incidence of poststroke epilepsy in Dr. Hasan Sadikin Hospital, Bandung.

Method: The case-control study was performed retrospectively from 1725 stroke patients in dr. Hasan Sadikin Hospital Bandung during the period of January 2014-December 2016. Mann-Whitney statistical analysis, Spearman rank and logistic regression were performed to see the relationship between neurological deficits during onset of stroke, patient age, location of lesions and stroke type on poststroke epilepsy. Neurologic deficits were assessed by National Institutes of Health Stroke Scale (NIHSS), location of lesions and stroke types assessed by Brain CT Scan or MRI, old age was $>60$ years.
\end{abstract}

Results: Poststroke epilepsy occurred in 53 patients, but only 47 patients met the case group criteria and 94 control group patients totaling 141 subjects. More than half (52.6\%) of cortical lesions had poststroke epilepsy. Severe neurologic deficits developed into poststroke epilepsies in 45.8\%. Stroke type and age did not influence the incidence of poststroke epilepsy $(p=0.843$, OR=0.93).

Discussion: Cortical lesions cause three-fold poststroke epilepsy and severe neurological deficits cause twice as many poststroke epilepsy events.

Keyword: Cortical lesion, poststroke epilepsy, severe neurological deficits

\section{ABSTRAK}

Pendahuluan: Stroke merupakan penyakit yang sering mengakibatkan epilepsi pada orang dewasa. Lokasi di kortikal, jenis stroke perdarahan, defisit neurologis yang berat serta usia tua merupakan faktor-faktor yang memengaruhi terjadinya epilepsi pascastroke.

Tujuan: Penelitian ini bertujuan untuk menganalisis faktor-faktor yang memengaruhi kejadian epilepsi pascastroke di RSUP Dr. Hasan Sadikin, Bandung.

Metode: Penelitian kasus kontrol dilakukan secara retrospektif pada 1725 pasien stroke di RSUP dr. Hasan Sadikin Bandung selama periode Januari 2014-Desember 2016. Analisis statistik Mann-Whitney, rank Spearman dan regresi logistik dilakukan untuk melihat hubungan antara defisit neurologis saat awitan stroke, usia pasien, lokasi lesi dan jenis stroke terhadap kejadian epilepsi pascastroke. Defisit neurologis dinilai dengan skor National Institute of Health Stroke Scale (NIHSS), lokasi lesi dan jenis stroke dinilai dengan CT scan otak atau MRI, usia tua adalah >60 tahun.

Hasil: Epilepsi pascastroke terjadi pada 53 pasien, tetapi hanya 47 pasien yang memenuhi kriteria kelompok kasus dan 94 pasien kelompok kontrol sehingga total 141 subjek penelitian. Sebanyak 52,6\% lesi stroke di kortikal menjadi epilepsi pascastroke. Defisit neurologis berat berkembang menjadi epilepsi pascastroke sebanyak 45,8\%. Jenis stroke dan usia tidak memengaruhi kejadian epilepsi pascastroke.

Diskusi: Lesi kortikal menghasilkan kejadian epilepsi pascastroke sebanyak tiga kali lipat dan defisit neurologis berat menghasilkan kejadian epilepsi pascastroke sebanyak dua kali lipat.

Kata kunci: Defisit neurologis berat, epilepsi pascastroke, lesi kortikal

*Departemen Neurologi FK Universitas Padjadjaran/RSUP Dr. Hasan Sadikin, Bandung. Korespondensi: dr.indra1711@gmail.com.

\section{PENDAHULUAN}

Stroke adalah penyebab tersering terjadinya epilepsi pada dewasa. Sebanyak $11,5 \%$ pasien stroke akan berkembang menjadi bangkitan pascastroke dalam lima tahun. Bangkitan pascastroke yang berulang dapat berkembang menjadi epilepsi pascastroke. ${ }^{1}$ Pada tahun 2013, kelompok kerja International League Against Epilepsy (ILAE) merevisi terminologi yang terkait dengan epileptogenesis. ${ }^{1}$ Epileptogenesis merujuk pada kondisi jaringan otak yang mampu menjadi sumber bangkitan spontan. Stroke merupakan penyakit yang 
menyebabkan lesi patologis yang dapat berkembang menjadi lesi epileptogenik. ${ }^{1}$

Tidak semua pasien stroke akan berkembang menjadi epilepsi pascastroke. Ada beberapa faktor yang berhubungan dengan kejadian epilepsi pascastroke di kemudian hari. Dari beberapa penelitian menunjukkan bahwa lokasi lesi stroke di kortikal, jenis stroke perdarahan, beratnya defisit neurologis serta usia tua ( $>60$ tahun) merupakan faktor-faktor yang memengaruhi terjadinya epilepsi pascastroke. ${ }^{2-4}$ Lokasi lesi di kortikal memberikan kemungkinan 3,83 kali lebih sering menjadi epilepsi pascastroke dibandingkan lesi di subkortikal. Stroke perdarahan yang akan menjadi epilepsi pascastroke sebanyak 10-15\%, hal ini lebih banyak dibandingkan stroke iskemik yang berkisar 6-9\%. Selain itu juga dilaporkan bahwa pasien stroke dengan defisit neurologis berat (skor NIHSS $\geq 15$ ) akan mengalami epilepsi pascastroke sebanyak 1,9 kali lebih sering dibandingkan pasien stroke dengan defisit neurologis ringan (skor NIHSS $\leq 14$ ). Penelitian dari Boovalingam melaporkan bahwa epilepsi pascastroke banyak terjadi pada pasien stroke usia tua ( $>60$ tahun). ${ }^{2}$

Epilepsi pascastroke memberikan kontribusi dalam luaran pasien stroke. Risiko terjadinya kematian dalam satu bulan pertama pada pasien epilepsi pascastroke adalah 13 kali lebih sering dibandingkan pasien stroke tanpa epilepsi pascastroke. Hari rawat di rumah sakit akan lebih panjang dan gejala sisa stroke akan lebih berat pada saat keluar rumah sakit. Hal ini tentu sangat menyulitkan proses rehabilitasi pascastroke. $^{2-5}$ Dengan mengetahui faktor-faktor risiko, kita akan mampu memperkirakan pasien stroke yang kemungkinan akan muncul kejadian epilepsi pascastroke di kemudian hari.

\section{TUJUAN}

Untuk mengetahui pengaruh lokasi lesi, jenis stroke, beratnya defisit neurologis dan usia pasien stroke terhadap kejadian epilepsi pascastroke.

\section{METODE}

Penelitian kasus kontrol retrospektif terhadap pasien stroke dengan epilepsi pascastroke. Sebagai kontrol adalah pasien stroke yang secara klinis tidak berkembang menjadi epilepsi pascastroke. Penelitian dilakukan pada tahun 2017 dengan menggunakan catatan rekam medis pasien rawat inap dan rawat jalan di Departemen Neurologi RSUP Dr. Hasan Sadikin, Bandung selama periode 3 tahun (Januari 2014 sampai dengan Desember 2016).

Kriteria inklusi adalah pasien stroke baik serangan pertama ataupun stroke ulang yang telah didiagnosis epilepsi pascastroke, dilakukan pemeriksaan CT scan otak atau MRI, EEG yang diinterpretasi oleh ahli EEG serta dilakukan skoring defisit neurologis berdasarkan NIHSS. Adapun yang tidak berkembang menjadi epilepsi pascastroke diinklusikan ke dalam kelompok kontrol.

Kriteria eksklusi yaitu pasien stroke dengan riwayat epilepsi sebelumnya, riwayat lesi intrakranial lain yaitu tumor intrakranial, infeksi intrakranial, pascaoperasi intrakranial, trauma kepala. Untuk kelompok kontrol, kriteria eksklusinya adalah yang mengalami bangkitan simptomatik pada fase akut stroke.

Lokasi lesi dan jenis stroke ditentukan oleh CT scan otak atau MRI. Defisit neurologis dinilai dengan skor NIHSS dan usia tua ditentukan $>60$ tahun. Analisis data diolah dengan menggunakan SPSS 20.0. Analisis bivariat untuk uji hipotesis variabel bebas dengan variabel tergantung berskala nominal dengan statistik Mann-Whitney dan analisis multivariat dengan regresi logistik. Tingkat hubungan antar variabel dinilai dengan rasio Odds dan tingkat kemaknaan dengan $\mathrm{p}<0,05$.

\section{HASIL}

Didapatkan 1.725 pasien yang terdiri dari 571 pasien stroke perdarahan dan 1.154 pasien stroke iskemik. Sebanyak 53 pasien $(3,07 \%)$ mengalami epilepsi pascastroke, namun hanya 47 pasien yang memenuhi kriteria inklusi dan tidak memiliki kriteria eksklusi. Kontrol sebanyak dua kali lipatnya yaitu 94 pasien sehingga total terdapat 141 subjek (Tabel 1). Subjek laki-laki $(48,22 \%)$ hampir berimbang dengan perempuan $(51,77 \%)$. Keduanya menghasilkan kemungkinan yang hampir sama untuk menjadi epilepsi pascastroke $(32,87 \%-35,93 \%)$. Terdapat $60,3 \%$ kelompok usia muda ( $\leq 60$ tahun) dan ada 
Tabel 1. Karakteristik Subjek Penelitian $(n=141)$

\begin{tabular}{|c|c|c|c|}
\hline \multirow{2}{*}{ Variabel } & \multicolumn{2}{|c|}{ Stroke } & \multirow{2}{*}{$\begin{array}{l}\text { Total } \\
\text { n (\%) }\end{array}$} \\
\hline & Epilepsi (+) & Epilepsi (-) & \\
\hline \multicolumn{4}{|l|}{ Jenis Kelamin } \\
\hline - Laki-laki & $23(35,93 \%)$ & $45(66,17 \%)$ & $68(48,22)$ \\
\hline - Perempuan & $24(32,87 \%)$ & $49(67,12 \%)$ & $73(51,77)$ \\
\hline \multicolumn{4}{|l|}{ Usia } \\
\hline - Tua $(>60)$ & $19(33,9 \%)$ & $37(66,1 \%)$ & $56(39,7)$ \\
\hline - Muda $(\leq 60)$ & $28(32,9 \%)$ & $57(67,1 \%)$ & $85(60,3)$ \\
\hline \multicolumn{4}{|l|}{ Jenis Stroke } \\
\hline - Perdarahan & $5(35,7 \%)$ & $9(64,3 \%)$ & $14(9,9)$ \\
\hline - Iskemik & $42(33,1 \%)$ & $85(66,9 \%)$ & $127(90,1)$ \\
\hline \multicolumn{4}{|l|}{ Lokasi Lesi } \\
\hline - Kortikal & $20(52,6 \%)$ & $18(47,4 \%)$ & $38(27)$ \\
\hline - Subkortikal & $27(26,2 \%)$ & $76(73,8 \%)$ & $103(73)$ \\
\hline \multicolumn{4}{|l|}{ Defisit Neurologis } \\
\hline - Berat (NIHSS $\geq 15$ ) & $22(45,8 \%)$ & $26(54,2 \%)$ & $48(34)$ \\
\hline - Ringan (NIHSS $\leq 14$ ) & $25(26,9 \%)$ & $68(73,1 \%)$ & $93(66)$ \\
\hline
\end{tabular}

NIHSS: National Institute of Health Stroke Scale.

$39,7 \%$ usia tua (>60 tahun). Kejadian epilepsi pascastroke pada kedua kelompok usia itu hampir sama yaitu 32\%-33\%. Jenis stroke iskemik sebanyak 127 subjek (90,1\%), jauh lebih banyak dibandingkan stroke perdarahan yaitu sebanyak 14 subjek $(9,9 \%)$. Namun, yang mengalami epilepsi pascastroke jumlahnya hampir sama yaitu $35,7 \%$ dari stroke perdarahan dan $33,1 \%$ dari stroke iskemik.
Lokasi stroke di kortikal terdapat pada 38 subjek dan sebanyak 52,6\% berkembang menjadi epilepsi pascastroke. Di lain pihak, lesi stroke di subkortikal sebanyak 103 pasien dan 26,2\% yang mengalami epilepsi pascastroke. Subjek penelitian dengan defisit neurologis berat sebanyak 48 subjek dan 45,8\% mengalami epilepsi pascastroke. Subjek penelitian dengan defisit neurologis ringan sebanyak

Tabel 2. Hasil Uji Hipotesis Faktor-faktor Risiko Epilepsi Pascastroke (n=141)

\begin{tabular}{|c|c|c|c|c|}
\hline \multirow{2}{*}{ Variabel } & \multicolumn{2}{|c|}{ Stroke } & \multirow{2}{*}{$\mathbf{p}^{*}$} & \multirow{2}{*}{$\begin{array}{c}\text { RO } \\
\text { (IK 95\%) }\end{array}$} \\
\hline & Epilepsi (+) & Epilepsi (-) & & \\
\hline \multicolumn{5}{|l|}{ Usia } \\
\hline - $>60$ tahun & $19(33,9 \%)$ & $37(66,1 \%)$ & 0,93 & 1,045 \\
\hline - $\leq 60$ tahun & $28(32,9 \%)$ & $57(67,1 \%)$ & & $(0,512-2,136)$ \\
\hline \multicolumn{5}{|l|}{ Jenis Stroke } \\
\hline - Perdarahan & $5(35,7 \%)$ & $9(64,3 \%)$ & 0,843 & 1,124 \\
\hline - Iskemik & $42(33,1 \%)$ & $85(66,9 \%)$ & & $(0,355-3,565)$ \\
\hline \multicolumn{5}{|l|}{ Lokasi Stroke } \\
\hline - Kortikal & $20(52,6 \%)$ & $18(47,4 \%)$ & 0,003 & 3,128 \\
\hline - Subkortikal & $27(26,2 \%)$ & $76(73,8 \%)$ & & $(1,443-6,779)$ \\
\hline \multicolumn{5}{|l|}{ Defisit Neurologis } \\
\hline - Berat & $22(45,8 \%)$ & $26(54,2 \%)$ & 0,024 & 2,302 \\
\hline - Ringan & $25(26,9 \%)$ & $68(73,1 \%)$ & & $(1,109-4,775)$ \\
\hline
\end{tabular}


Tabel 3. Analisis Multivariat untuk Melihat Hubungan antara Lokasi Stroke dan Defisit Neurologis dengan Kejadian Epilepsi Pascastroke Berdasarkan Analisis Regresi Logistik

\begin{tabular}{lccc}
\hline \multicolumn{1}{c}{ Variabel } & Koefisien (B) & Nilai p & $\operatorname{Exp~(B)~}$ \\
\hline Langkah 1 & & & \\
- Lokasi stroke & 0,939 & 0,029 & 2,557 \\
- Defisit neurologis & 0,487 & 0,236 & 1,626 \\
- Konstanta & $-1,153$ & 0 & 0,316 \\
Langkah 2 & & & \\
- Lokasi stroke & 1,14 & 0,004 & 3,128 \\
- Konstanta & $-1,035$ & 0 & 0,355 \\
\hline Exp (B): besarnya pengaruh; $0:$ rasio Odds &
\end{tabular}

Exp (B): besarnya pengaruh; RO: rasio Odds.

93 subjek dan 26,9\% yang mengalami epilepsi pascastroke (Tabel 2). Subjek dengan lesi di kortikal berisiko 3,128 kali untuk mengalami epilepsi pascastroke secara signifikan dibandingkan subjek dengan lesi di subkortikal $(\mathrm{p}=0,003)$. Demikian pula subjek dengan defisit neurologis berat berisiko 2,3 kali untuk menjadi epilepsi pascastroke secara signifikan dibandingkan subjek dengan defisit neurologis ringan $(\mathrm{p}=0,024)$. Adapun jenis stroke dan usia tidak bermakna secara statistik $(p>0,05)$.

Analisis multivariat dilakukan terhadap variabel lokasi lesi dan defisit neurologis (Tabel 3). Lokasi lesi stroke di kortikal merupakan satusatunya faktor risiko yang paling memiliki pengaruh signifikan terhadap kejadian epilepsi pascastroke sebanyak 3,128 kali dibandingkan lesi di subkortikal $(\mathrm{p}=0,004)$.

\section{PEMBAHASAN}

Lokasi stroke di kortikal berkembang dilakukan Chiang dkk menjadi epilepsi pascastroke sebanyak $52,6 \%$, sedangkan stroke di subkortikal 26,2\% yang berkembang menjadi epilepsi pascastroke. Hal ini sesuai dengan penelitian Boovalingan, dkk yaitu sebanyak 54\% stroke di kortikal dan 19\% stroke di subkortikal menjadi epilepsi pascastroke di kemudian hari. $^{2}$

Lokasi lesi di kortikal memiliki hubungan yang bermakna dengan kejadian epilepsi pascastroke dan memberikan kemungkinan 3,128 kali lipat dibandingkan lesi di subkortikal. Hal ini sesuai dengan penelitian multisenter internasional yang menunjukan kemungkinan lesi kortikal yang akan berkembang menjadi epilepsi pascastroke sebanyak 3,83 kali lipat. Hasil ini didukung pula oleh penelitian lain yang di Taiwan pada pasien stroke awitan pertama kali menunjukkan bahwa lesi di kortikal memiliki kemungkinan 5,5 kali lipat menjadi epilepsi pascastroke dibandingkan lesi di subkortikal. Begitu pula penelitian yang dilakukan Osvaldo dkk, Alberti, dan Kim yang melaporkan lesi di kortikal akan mengalami epilepsi di kemudian hari masing-masing 2,09; 2,54 dan 5,27 kali lipat dibandingkan lesi di subkortikal. ${ }^{1,6-9}$

Tidak semua stroke kortikal mengalami kejadian epilepsi pascastroke. Hal ini bisa dipahami karena tidak semua lesi stroke di area kortikal mudah untuk menjadi lesi epileptogenik, tergantung lapis mana dari korteks yang terkena stroke. Lapis kelima (piramida interna) dari korteks merupakan daerah paling rentan menjadi lesi epileptogenik karena struktur sel piramida yang banyak dan besar serta jangkauan aksonnya yang jauh sampai ke lapis kesatu korteks dan daerah subkortikal. ${ }^{10}$ Defisit neurologis berat akan berkembang menjadi epilepsi pascastroke sebanyak 2,3 kali lipat dibandingkan defisit neurologis ringan. Hal ini juga sesuai dengan data penelitian sebelumnya yang menunjukkan bahwa defisit neurologis berat memiliki kemungkinan untuk menjadi epilepsi pascastroke sebanyak 1,9 kali lipat dibandingkan defisit neurologis ringan. ${ }^{9}$

Skor NIHSS terdiri dari 11 komponen penilaian meliputi: tingkat kesadaran, gerak bola mata, lapang pandang, paresis otot-otot wajah, fungsi motorik lengan dan tungkai, ataksia, sensorik, bahasa, disartri, ekstinsi dan inatensi (neglect). Komponen penilaian dari NIHSS ini lebih banyak menggambarkan tingkat keparahan lesi stroke di kortikal, sehingga sangat mungkin akan tumpang tindih (overlaping) dengan faktor risiko lokasi lesi di kortikal. ${ }^{11-13}$ Kejadian epilepsi pascastroke pada kedua kelompok usia baik usia tua ( $>60$ tahun) dan usia muda ( $\leq 60$ tahun) memperlihatkan tidak ada hubungan bermakna $(\mathrm{p}>0,05)$. Hal ini berbeda dengan penelitian lain yang melaporkan pasien stroke usia $>60$ tahun akan berkembang menjadi epilepsi pascastroke sebanyak 77\%. Namun, penelitian di Kanada pada 5.027 pasien 
menyimpulkan bahwa tidak ada perbedaan bermakna antara usia tua dan usia muda ( $<60$ tahun, 60-79 tahun, dan $>79$ tahun) terhadap kejadian epilepsi pascastroke. ${ }^{1,14-15}$

Perbedaan hasil ini dimungkinkan karena proporsi subjek penelitian usia muda $(60,3 \%)$ yang lebih banyak dibandingkan usia tua $(39,7 \%)$. Hal ini berbeda dengan penelitian di luar negri yang memiliki subjek penelitian usia tua ( $>60$ tahun) yang lebih dominan dibandingkan usia muda. , 14-15 $^{1}$

Jenis stroke terdiri dari stroke iskemik sebanyak 127 subjek $(90,1 \%)$ dan stroke perdarahan sebanyak 14 subjek (9,9\%). Namun, yang mengalami epilepsi pascastroke jumlahnya hampir sama yaitu $35,7 \%$ dari stroke perdarahan dan $33,1 \%$ dari stroke iskemik. Hasil uji hipotesis mengenai jenis stroke pada penelitian ini tidak menunjukkan hubungan bermakna dengan kejadian epilepsi pascastroke $(\mathrm{p}>0,05)$. Hal ini berbeda dengan hasil penelitian sebelumnya yang menunjukkan bahwa kedua jenis stroke bisa menyebabkan epilepsi pascastroke dengan presentase stroke perdarahan lebih banyak (10\%-15\%) dibandingkan stroke iskemik (6\%-9\%). ${ }^{2}$

Stroke perdarahan lebih banyak berkembang menjadi epilepsi pascastroke karena kondisi yang merusak sawar darah otak. Dari penelitian lain sebanyak 28 pasien epilepsi pascastroke perdarahan dengan rentang usia 38-90 tahun dilakukan pemeriksaan pewarnaan TC-dietilen triamin penta asam asetat oleh Single Photon Emission Computed Tomography (SPECT) diperoleh hasil 86\% sawar darah otaknya rusak. Hal ini dibandingkan dengan kelompok kontrol (pasien stroke perdarahan tanpa epilepsi pascastroke) yang hanya 29\% mengalami kerusakan sawar darah otak. Kerusakan sawar darah otak ini dipengaruhi oleh mediator inflamasi yang dikeluarkan (sitokin dan kemokin), trombin, hemoglobin dan zat hasil pemecahannya, stres oksidatif, komplemen dan matrix metalloproteinases. Kondisi kerusakan ini menyebabkan pembentukan edema yang lebih hebat, masuknya leukosit dan agen neuroaktif pada daerah perihematom yang berkontribusi terhadap terjadinya jejas di otak. Hal inilah yang membuat stroke perdarahan lebih rentan mengalami kejadian epilepsi pascastroke, apalagi jika lokasi perdarahan di kortikal. ${ }^{1}$

Kondisi hasil penelitian yang menunjukkan tidak ada hubungan bermakna antara jenis stroke dengan kejadian epilepsi pascastroke mungkin disebabkan oleh proporsi subjek penelitian antara stroke iskemik dan perdarahan yang tidak seimbang yaitu 90,1\% stroke iskemik dan 9,9\% stroke perdarahan. Kondisi proporsi yang tidak seimbang ini menghasilkan persentase yang hampir sama antara stroke iskemik dan stroke perdarahan (33,1\%-35,7\%) untuk menjadi epilepsi pascastroke di kemudian hari. Jenis kelamin pada penelitian ini seimbang antara laki-laki dan perempuan dengan persentase 35,93\% laki-laki yang mengalami epilepsi pascastroke dan $32,43 \%$ perempuan yang mengalami epilepsi pascastroke. Hal ini sesuai dengan penelitian di Kanada (2003-2005) yang menunjukkan bahwa proporsi laki-laki dan perempuan yang berkembang menjadi epilepsi pascastroke seimbang dan tidak memiliki hubungan bermakna terhadap kejadian epilepsi di kemudian hari. ${ }^{2}$ Dari analisis multivariat diperoleh hanya satu faktor yang paling signifikan memengaruhi kejadian epilepsi pascastroke yaitu lokasi lesi di kortikal.

Penelitian ini memiliki keterbatasan yaitu pasien yang dirawat di nama tempat diedit oleh redaksi sementara yang menjadi subjek penelitian memiliki proporsi yang tidak berimbang antara stroke iskemik dan stroke perdarahan. Selain itu faktor luas lesi juga merupakan salah satu keterbatasan karena pada penelitian ini tidak dimasukan ke dalam faktor yang memengaruhi kejadian epilepsi pascastroke.

\section{KESIMPULAN}

Lesi kortikal merupakan faktor yang paling memengaruhi kejadian epilepsi pascastroke dan memberikan kemungkinan 3 kali lebih sering menjadi epilepsi pascastroke dibandingkan lesi subkortikal. Beratnya defisit neurologis memengaruhi kejadian epilepsi pascastroke dan meningkatkan angka kejadian epilepsi pascastroke sebanyak 2 kali lipat.

\section{DAFTAR PUSTAKA}

1. Asla P, Reina R, Katarzyna L. Development of epilepsy after ischaemic stroke. Lancet Neurol. 2016;15:185-97. 
2. Boovalingam P, Witherall R, Ho CL, Nagarajan R, Ardron M. Post-stroke epilepsy. GMJournal. 2012; 1:33-9.

3. Arntz RM, Rutten-Jacobs LCA, Maaijwee NA, Schoonderwaldt HC, Dorresteijn LDA, Van-Dijk EJ, $\mathrm{dkk}$. Post stroke epilepsy in young adult: a long term follow up study. PloS One. 2013;8(2);1-8.

4. Zelano J, Redfors P, Asberg S, Kumlien E. Association between poststroke epilepsy and death: A nationwide cohort study. European Stroke Journal. 2016;1(4):272-8.

5. Arntz RM, Rutten-Jacobs LCA, Maaijwee NA, Schoonderwaldt HC, Dorresteijn LDA, Van-Dijk EJ, dkk. Poststroke epilepsy is associated with a high mortality after a stroke at young age. Stroke. 2015;46:2309-11.

6. Chiang IH, Chang WN, Lin WC, Chuang YC, Chang $\mathrm{KC}$, Tsai NW, dkk. Risk factors for seizure after firsttime ischemic stroke by magnetic resonance imaging. Acta Neurol Taiwan. 2010;19(1):26-32

7. Osvaldo C, Larry BG. Seizures and epilepsy after ischemic stroke. Stroke. 2004;35:1769-75.

8. Alberti, Paciaroni, Caso, Venti, Palmerini, Agnessi. Early seizures in patients with acute stroke: frequency, predictive factors, and effects of clinical outcome. Vascular Health And Risk Management. 2008;4(3):715-20.
9. Kim HJ, Park KD, Choi KG, Lee HW. Clinical predictors of seizure reccurence after the first post-ischemic stroke seizure. BMC Neurology. 2016;16:212-22.

10. Dachet F, Bagla S, Aviram GK, Morton A, Balan K, Saadat L. Predicting novel histopathological microlesions in human epileptic brain through transcriptional clustering. Brain . 2015;138:356-70.

11. Jojang H, Runtuwene T, Maja. Perbandingan NIHSS pada pasien stroke hemoragik dan non-hemoragik yang rawat inap di Bagian Neurologi RSUP Prof. Dr. R. D. Kandou Manado. eCl . 2016;4(1):1-4.

12. Conrad, Pawlowski, Dogan, Kovac, Ritter, Evers. Seizure after cerebrovascular events: Risk factors and clinical features. Seizure. 2013;22:275-82.

13. Sucharew H, Khoury J, Moomaw CJ, Alwell K, Kissela BM, Belagaje S. Profiles of the National Institutes of Health Stroke Scale items as a predictor of patient outcome. Stroke. . 2013;44(8): 2182-7.

14. Miskov AN, Bonjak J, Roje-Bedekov M, Mikula I, Deazmalj-Grbelja L, Kopaevi L, dkk. Strokethe most important cause of the newly diagnosed epilepsy in the elderly. Periodicum Biologorum . 2012;114(3):429-33.

15. Shasha L, Weihua Y, Yang L. The causes of new-onset epilepsy and seizures in the elderly. Neuropsychiatric Disease and Treatment. 2016;12:1425-34. 